\title{
The Relationship between Perceived Job Satisfaction, Commitment and Loyalty in Banking Sector
}

\author{
Yafra Naz*, Sadhna Lohano**, Abeer Khatri***
}

\begin{abstract}
In the current era of highly volatile corporate environment, organizations are facing challenges in the form of optimization of human resources in the banking sector of Pakistan. Human resources are measured as a source of ecological competitive advantage. The success of an organization depends upon several factors but the most decisive factor that effect the organizational performance and its employees. Job satisfaction is one of the most broadly discussed and devotedly studied paradigms in related disciplines such as industrial-organizational psychology, organizational behavior. The job satisfaction is the favorable or un-favorable attitude with which the employee views his and her work. Job satisfaction, thus, is the result of various attitudes possessed by an employee. The current study is in endeavor to observe and explore the impact of human resources practices on job satisfaction, Commitment \& loyalty of private and public sector banking employees. In the study the scientific management model, identify that Human resource management practices like training performance appraisal teamwork and compensation has significant impact on job satisfaction.
\end{abstract}

Keywords: Human resource management practices, Job satisfaction, Employee participation.

JEL Classification: G21, M14

\section{INTRODUCTION}

Numerous organizations understood that representatives are association's best resources that they can contend with inward and outer associations in their parts (Bailey et al., 2016). Job satisfaction has been defined as a gratifying emotional state-run subsequent from an assessment of one's job an actual reaction to one's job and a boldness towards one's job. Weiss (2002) has claimed that job satisfaction is an attitude but points out that academics should clearly distinguish the substances of cerebral appraisal, which are affected emotion, believes and behaviors.

Occupation or work is a significant part of a person's life and it possesses a tons of individual and expert time related to some other movement. It gives the monetary premise to an individual's life (Santhapparaj \& Alam, 2005). Warr Cook and Divider (1979) have characterized the activity and separate it with exertion as employment to the mission attempted in a specific circumstance while, work is taken to cover work all the more for the most part. Occupation can be taken a gander at as the methods used to achieve individual objectives identifying with one's profession. Then again,

* MSPM Scholar, Faculty of Management Sciences, Shaheed Zulfiqar Ali Bhutto Institute of Science and Technology, Karachi, Pakistan.Email:yafrakhan786@gmail.com (Corresponding Author)

** MSPM Scholar, Faculty of Management Sciences, Shaheed Zulfiqar Ali Bhutto Institute of Science and Technology, Karachi, Pakistan

*** MSPM Scholar, Faculty of Management Sciences, Shabeed Zulfigar Ali Bhutto Institute of Science and Technology, Karachi, Pakistan. 
fulfillment is the joy felt after a need is fulfilled (Robbins \& Stephen, 1998). Fulfillment, as characterized by Thorndike and Barnhart (1979), is the "satisfaction of conditions or wants".

Human resource management is the tenure use to denote to the philosophy rules process and performs related to the management of the persons begin an organization. Today each organization has to face high rivalry. Therefore, organizations try to do the right thing at the right time. In that circumstances, Human resource management plays a major role to achieve organizations goals satisfaction is one of the major concepts in Human resource management.

Human asset the board and their arrangements and strategy including Human Resource the executives parts of the board with respect to, arranging, enlistment, choice, preparing and advancement, execution examination and work relations (Dessler, 2007). Likewise, Lee and heard (2000) recommended that Human asset the executives rehearses are the authoritative resources that help an association to remain its viability. It's considered as a significant device to change the worker demeanor, conduct and occupation fulfillment, and the more significant is an authoritative duty. Thus, Human Resource Management is the piece of approaches, methodology, guidelines, that decides worker conduct disposition and execution (Noe, Hollenbeck, Gerhart \& Wright, 2007).

It is tied in with discovering, assessing, and communicating individual to function as staffing (Harel, 1996) moreover enlisting and choosing with the benefits of the association (Terpstra \& Rozell, 1993). Snell and Bohlander (2007) summarized that Training implies any action that is started by associations to advance learning inside the associations among individuals. As indicated by Snell and Bohlander (2007), all the organizations of pay, rewards, and advantages that are gotten by the representative is remuneration. Execution is a formalized cycle wherein we checked by work observing and it's considered as an administration device to recuperate the worker execution and efficiency (Shahzad, Bashir, \& Ramay, 2008).

The practice of the organizations about their employees' commitment is different if we compare the past to the present (Madi, Abu-Jarad \& Alqahtani, 2012). Previously, organization secured the loyalty of their employees by guaranteeing job security. However, Madi et al. (2012) maintained that many organizations have practiced downsizing, restructuring and transformation as a response to competitive pressures. Typically, Job fulfillment can be estranged into two distinct sorts for example extraneous occupation fulfillment and characteristic employment fulfillment (Clark, Oswald, \& Warr, 1996). Extraneous occupation fulfillment alludes to material parts of work and connected with outside hotspots for representatives, for instance, pay colleagues, retirement, medical coverage advantages and oversight. While inherent employment fulfillment is connected with inside sources, for instance, work intricacy, measure of obligation, aptitude use, having the option to help other people, getting a charge out of ones errands and difficulties (Currie \& Hill, 2012; Luna, Arocas, \& Morley, 2015).

Authority additionally assumes a significant part in deciding representatives' responsibility. Specialists have discovered that representatives who are satisfied with their administrators/chiefs and feel that they are being treated with deference and are esteemed by their administration feel greater connection with their associations (Stup, 2006). The achievement of an association relies upon dedicated, faithful and submitted representatives, where work fulfillment is the passionate reaction of workers towards their activity or experience (Kazi \& Zadeh, 2011; Irfan et al., 2013). 


\section{Theory and its Implications and Benefits}

Fredrick Taylor the scientific management theory, which highlighted on job competences, through penetrating for the 'unique way' to do each job. He established a collection of values toward improve to recover efficiency in organizations as well as created a mental among employees and managers. Some of the followers he industrialized contains numerous remuneration and extra motivation tactics. He also advances conducts of collective efficiency by production effort easier to do and approaches for inspiring the employees. Taylor standard that scientific management would require a wide-ranging cerebral uprising on the fragment of both organization also employees. On the chunk of organization, the scientific method required the principals.

1. Develop a knowledge for individually operation to substitute estimation and rule-ofthumb.

2. Regulate precisely from the discipline the right time and technique for each work.

3. Munificently help the laborers in order to guarantee that all work is done as per the principles of the science that has been created.

4. Separation work and duty likewise among the board and laborers. The managers assumes control over all work for which it is preferred tailored over the laborers.

\section{Implementing Scientific Management Principles for Enhanced Performance in Banking Sector}

In scientific management principles to increase productivity and efficiency in banking sector, the management of banks must work according to scientific byelaws and specific techniques, which every employee should be communicated what is required of him in terms of objective and targets to be completed. Fringe benefits is the measureable and unmeasurable enticements the corporation suggest to its workforces to compel them to the corporation. In other words fringe benefits are enticements that employee received in adding to their wages and remunerations during dynamic job duty and in accumulation after leaving. HR observes strongly affect the service quality in three different channels, first control-based channel is used to boost efficiency and productivity, furthermore awareness base channel to comfortable service distribution process and third motivational based to increase employee satisfaction and security through best HR and organizational rules and regulations. The significance of employee commitment in the workplace has been recognized since a long period. The performance of an institute exceedingly be contingent on the assurance of its personnel; more the personnel are dedicated, enhanced the enactment of the entire institute. Job envelopment is also measured as an important workforces job related performance and has been defined as a worker's psychosomatic proof of identity or guarantee to the job. It is very important to communication that worker like to take part in management and this involvement lead to job satisfaction. Involvement in executive accomplish the need of workers' self-esteem and employee deeds will be supportive towards organizational goals.

The notion of given right and autonomy to the individuals who are worker can be searched easily from diverse places, as per friend tactic join two classes of work in a strategic process. Remuneration and appreciation is seen as the main dominant aspect of job satisfaction. Lack or simple incentive and appreciation structure have adverse impression on job satisfaction. Remuneration and appreciation has optimistic relation to job satisfaction in a training led in financial sector. In core, discoveries by different scholars call for super vision to improve incentive and appreciation in order to have better effect on employee satisfaction. According to research that as Pakistan is developing day by day, its work atmosphere is also suitable good. In this reasonable market, bosses demand extremely dedicated employees. Employee's commitment be contingent upon their gratification with their pay packages, job and connections with other workers. Employee gratification is a degree of how pleased and cheerful employees are with their job and functioning atmosphere keeping confidence 
from top to bottom among workers can be of incredible advantage to any company, as blissful employees will be more likely to produce more, take less days of at stay faithful to the corporation. Hence, many influences educating high employee satisfaction, which wise bosses, would do well to implement.

Job satisfaction is referred as the key area which has consideration of scholars and organizational employees. It can be stated that job satisfaction is the way of expressing the response of any individual from his/her work or job. Job satisfaction can be further determined as the delightful emotional state which is resulted due to an individual's job experience. However, job satisfaction ensures the organizational accomplishment as it leads to effective organizational commitment and job performance. There are three opportunities recognized by the researchers including; normative, affective and continuance commitment. Affective assurance is known as the key method of encouraging the participation of employees for their organizations.

To stay with the institute in long term can be determined as employee loyalty. It is further defined as quantity by the amount of time one has given for the organization.

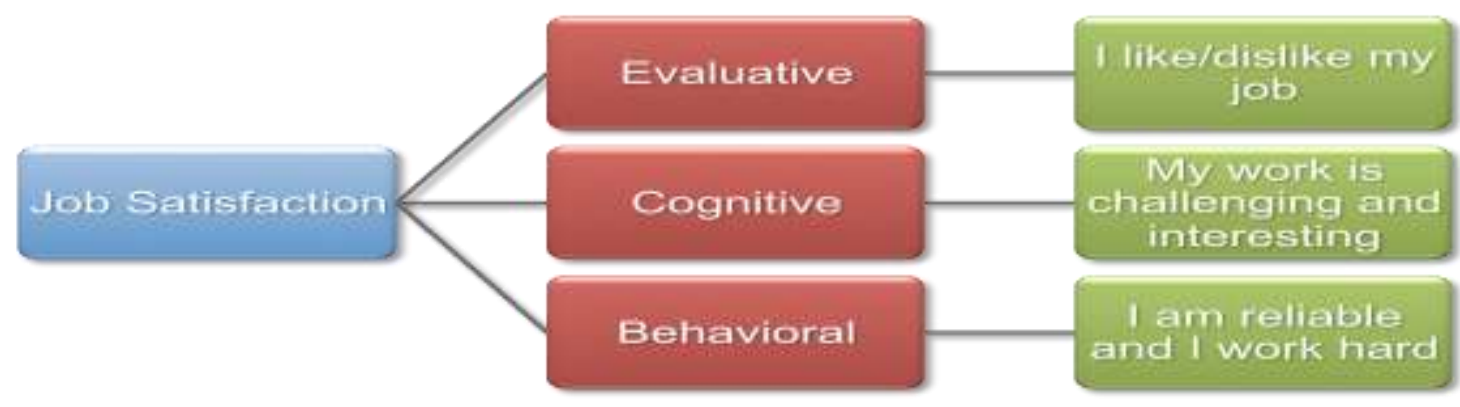

Figure 1: Components of Job Satisfaction

\section{Theory and Key Concepts}

Earlier the Industrialized Rebellion, maximum organizations were diminutive responsibilities, be an average of three or four people. Owners as often as possible worked beside representatives, comprehended what they were organized to do, and decisively conforming their work. The basics of the work atmosphere changed drastically with the Mechanical Transformation. Chiefs didn't have convenient connotations with their workers. The employees "on the floor" skillful the work technique and by and large malformed down enough to ensure they would not be dismissed. There is zero incentive to work more ardently than the subsequent man or women.

In 1909, Taylor distributed The Standards of Logical Administration. He recommended that profitability would increment if employments were upgraded and rearranged. Taylor previously built up splitting each activity into sections and timing each part to select the fruitful technique for working. Straight to the point and Lillian Gilbreth, concocted recording laborers to dissect their movements.

It is analyzed that key approach of Taylor was structured to use in different places were the work can be systemized, institutionalized and evaluated such as; industrial facilities. As the employees were not urged to assess happenings which can deliver a superior outcome so in logical administration, this is one right approach to carry out a responsibility. The big point of worry for Taylor other than inspiration and professional fulfilment was the yield. Taylor's work presented just because the opportunity of deliberate preparing and choice, and it urged entrepreneurs to work with legislatures to build profitability and productivity. Moreover, to set the standard about an expert ought to have 
the option of deliver in a set timeframe; Taylor presented the idea of "five star employee". hence, as in eminence logical supervision is developed among huge organizations since the rise in profitability, demonstrating that it worked.

Today, advanced Taylorism remain contingent on increasing efficacy by institutionalizing the devices and methods for final to each assignment associated with a given motion. Each task is disjointed to the tiniest crusade and transformed into an accurate system that must be followed to polish that undertaking. In the meantime, everyone is working in the equivalent thoughtless way, it is shapes reliability and consistency though decreasing blunders. It is moderately simple for troughs to displace laborers and hold a related productivity. The study of this thoughtful of the panel tactic is like that Taylor's exclusive theory: it diminishes professional innovativeness; it assumes the panel to monitor all parts of descriptive behavior; and it is demanding to workers who do not satisfy with the standard.

\section{Correlation between Job Satisfaction, Commitment and Loyalty}

Although research scrutinizing the correlation among job satisfaction commitment and loyalty, in order to connecting relationship between job satisfaction commitment and loyalty has been clearly proven. Many researchers have linked job satisfaction, commitment and loyalty and recognized a strong positive connection between job satisfactions, commitment and loyalty with statistics from bank.

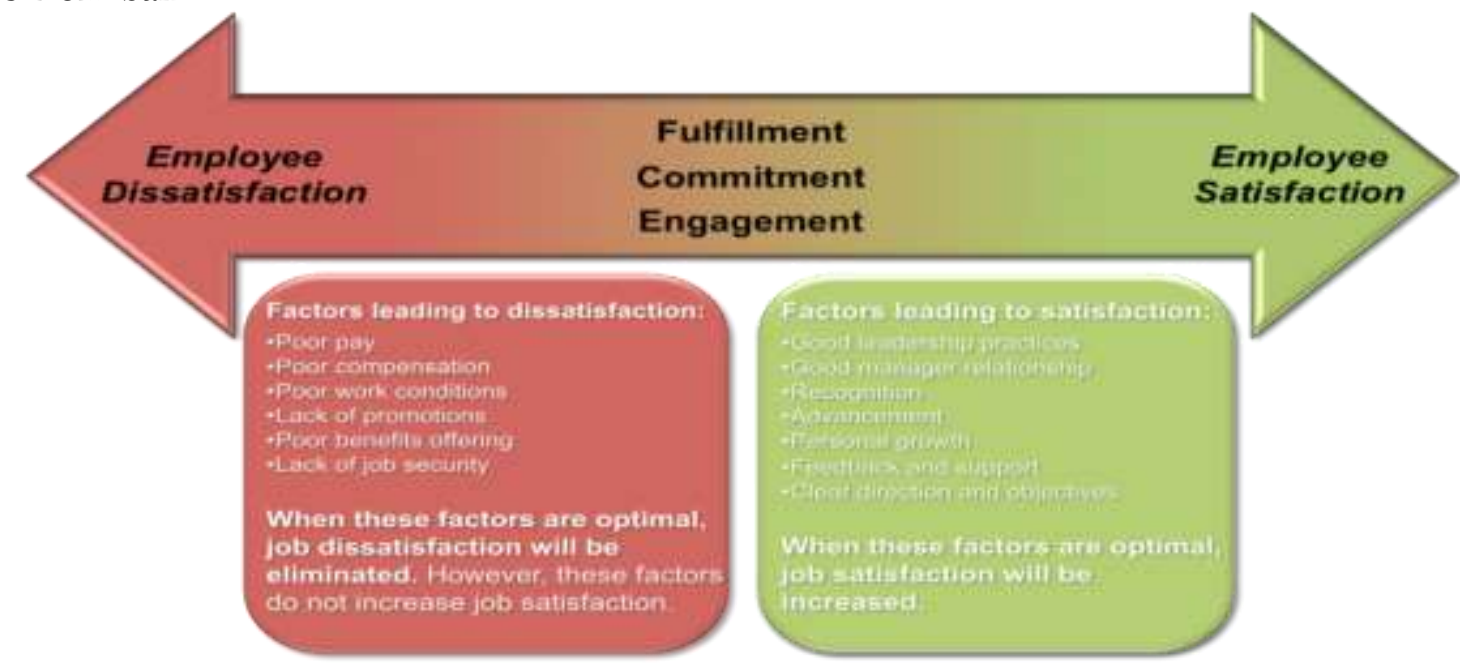

Figure 2: Job Satisfaction Model

\section{Need for Study}

This research was comprising to distinguish which are significant issues that have most impact on representative employee job satisfaction commitment and loyalty. This study strained to clarify the direct and indirect special effects on employee loyalty and commitment through their job satisfaction. Based on results, enhancement and growth suggestions to banking associations will gave as reasonable rules to upgrade representatives' fulfillment and their devotion.

\section{Objectives of The Study}

The correlation between employees' job satisfaction, commitment and loyalty in banking sector is the core objective of our research.

- To determine connection between employee motivation and training and development

- $\quad$ To study about the link between employee motivation and employee commitment

- To scrutinize affiliation among employee motivation and Job security

- $\quad$ To notice connotation among employee motivation and workplace atmosphere. 


\section{Purpose}

The effect of job refuge, drill and growth, work place condition, and investment in basic leadership on work fulfillment, duty and faithfulness. Also, decide the connection among motivators and representative responsibility and detail suggestions with respect to work fulfillment, duty and reliability.

\section{Problems}

Several issues, which influence representatives in the organizations. In case of pledge, participation and assignation of workers in effort are mostly connected with the dominant values and atmosphere in the organization. Therefore, problematic declaration of study expressed as follows:

1. Study designates important connection of emotional authorization with organizational obligation.

2. The banking subdivision of Pakistan, throughout the initial study is calm facts that revenue in banking sector has been at its top during the current period.

1.8 Financial Highlights of The Company/Sector

Total resources increased from PKR 3,025,853,150 to 3,195,697,439 in six months (Dec 31, 2018 to Jun 30 2019). While Income after tax system is 3,927,302.

The combination of fiscal and monetary policies employed in FY'19 to stabilize the economy will dampen domestic demand and growth. Higher energy prices, multiple rounds of currency adjustment and import compression policies have resulted in sustained upward pressure on prices. HBL has revealed a 9M'19 Profit before Tax of Rs 18.3 billion, 3\% higher than for a similar period a year ago. This is regardless of the critical effect of the falling Rupee and the value market, which have together diminished pre-charge benefit by Rs 7.4 billion. Benefit after assessment of Rs 8.8 billion for 9M'19 is, notwithstanding, Rs 1.1 billion lower than a year ago, because of the review inconvenience of Rs 1.9 billion of Super Tax on 2017 profit. HBL's profit per share for 9M'19 are at Rs 5.89.

$\mathrm{HBL}$ continues to receive multiple international awards. Asia money awarded HBL as the Local Bank in the Region for Belt \& Road Initiative (BRI), Best Individual BRI Project/Initiative in the Region, and Best Corporate Finance House - Fixed Income. HBL's emphasis on gender diversity and presence was recognized by the Asian Development Bank who awarded HBL the admired Gender Champion Award. For the fourth year running, HBL received the Brand of the Year, Banking Pakistan, at the World Branding Awards.

\section{Sector Brief}

Providing for the Mid-year Performance Review of the financial part gave by the state Bank of Pakistan on 21st October 2019, banking segment held its movement direction during the main portion of 2019 because of fair increment in stores, on account of an absolution conspire reported by the administration. On the legal responsibility side, store development quickened to 6.8 percent during January-June, 2019, up from 5.7 percent in the equivalent time of a year ago. A decent segment of these stores was set up in June, 2019 leaving a next to no an ideal opportunity to convey the assets in higher versatile income resources. On the advantages side, private part progresses saw an expansive based stoppage while public area propels declining because of lesser use of administration financing and withdrawal of energy segment progresses. Further, banks borrowings declined by 12.7 percent and advances to store proportion dunked to 53.2 in June, 2019 contrasted with 55.8 in December, 2018. 


\section{PRACTICAL IMPLICATIONS}

This survey is design to use open-ended questions for greater insights. Open-ended questions are greater for getting authentic feedback because they give people a chance to describe what they are experiencing in their own voice.

\section{Research Process}

The questionnaire used in the current research. Being a qualitative henceforth, the employees' answer and opinions crucial for the study, it enables the scientist to get in close contact with the respondents to appreciate the issue from inside. Moreover, the specialist is helped to give the understanding and examination of the present discoveries. The analysts watched different things from assorted measurements using survey (Schwartzman, 1993). Head of Talent Acquisition were interviewed via face-to-face approx. 15 minutes. The designed questionnaire comprised on 13 items. The open questions were part of the interview to allow respondents an opportunity to deliberate their individual point of view.

\section{SWOT Analysis of The Company}

Research is very significant for the organization in recollecting the strength, overcoming the faults, exploiting over developing market chances, and desire ways to effectively challenge by the intimidations \& eventually changing them in assets for the organization.

\begin{tabular}{|c|c|}
\hline Strengths & Weaknesses \\
\hline $\begin{array}{l}\text { The pioneer of banking in Pakistan, Habib bank } \\
\text { is seasoned and prodigal in Knowledge. } \\
\text { HBL can possibly experience the intensive } \\
\text { condition in the marketplace. } \\
\text { The management of the bank has confidence in } \\
\text { client centered banking as divergent to } \\
\text { The item situated banking. The item and } \\
\text { management designed by the bank are } \\
\text { extraordinarily modified to the individual needs } \\
\text { of its clients. } \\
\text { The results of HBL is likewise its quality. HBL } \\
\text { has numerous items for practically a Wide range } \\
\text { of clients. In this way, it relies upon the client } \\
\text { that which item he/she like and in part, he needs } \\
\text { to contribute contingent upon whether an } \\
\text { individual is salaried one or a businessman. } \\
\text { It has the leading branch arrangements amongst } \\
\text { private banks of Pakistan. }\end{array}$ & $\begin{array}{l}\text { Lack of communication between bank and } \\
\text { customers about positions and situation of } \\
\text { product \& services. Similar centralism of cheque } \\
\text { book distributing method. } \\
\text { Low paces of enthusiasm on stores } \\
\text { Centralized supervision in specific areas } \\
\text { Wide territory to deal. } \\
\text { Lack of data knowledge. }\end{array}$ \\
\hline Opportunities & Threats \\
\hline $\begin{array}{l}\text { A huge quantity of speculation is appealing with } \\
\text { other banks } \\
\text { Islamic banking is a growing business sector } \\
\text { fragment that deals likeable probablities to } \\
\text { prospectivel and present customers. } \\
\text { Improved special strategies } \\
\text { Habib bank limited distinguish and increase it } \\
\text { payment by offering striking rates on credits. }\end{array}$ & $\begin{array}{l}\text { Facing more challenge by distant banks in } \\
\text { markets. } \\
\text { Compact area network and banking } \\
\text { Improved rules from state bank of Pakistan may } \\
\text { influence its business. }\end{array}$ \\
\hline
\end{tabular}

Figure 3: SWOT Analysis 


\section{Products of the Company}

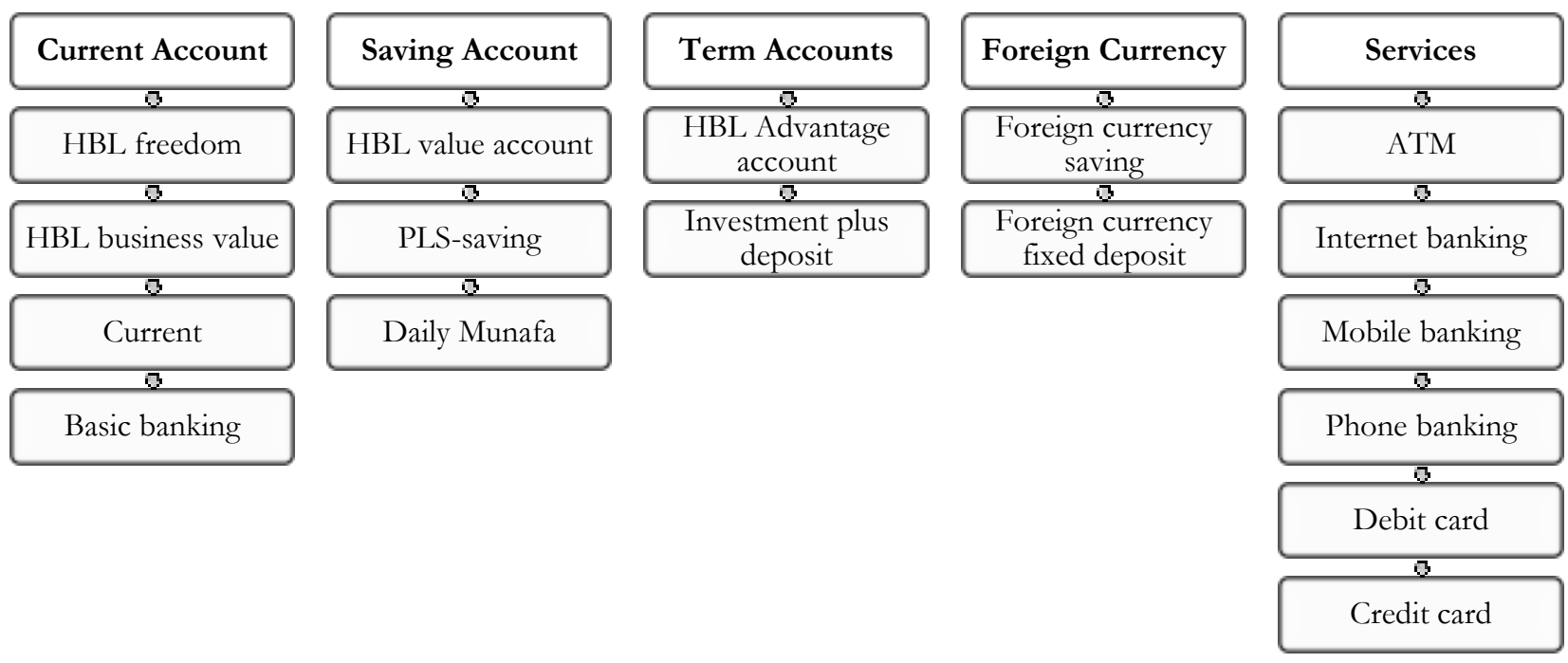

Figure 4: HBL Products

Habib Bank Limited Offer a Range of Products and Services to Expedite the Demands of Fi/Nbfi
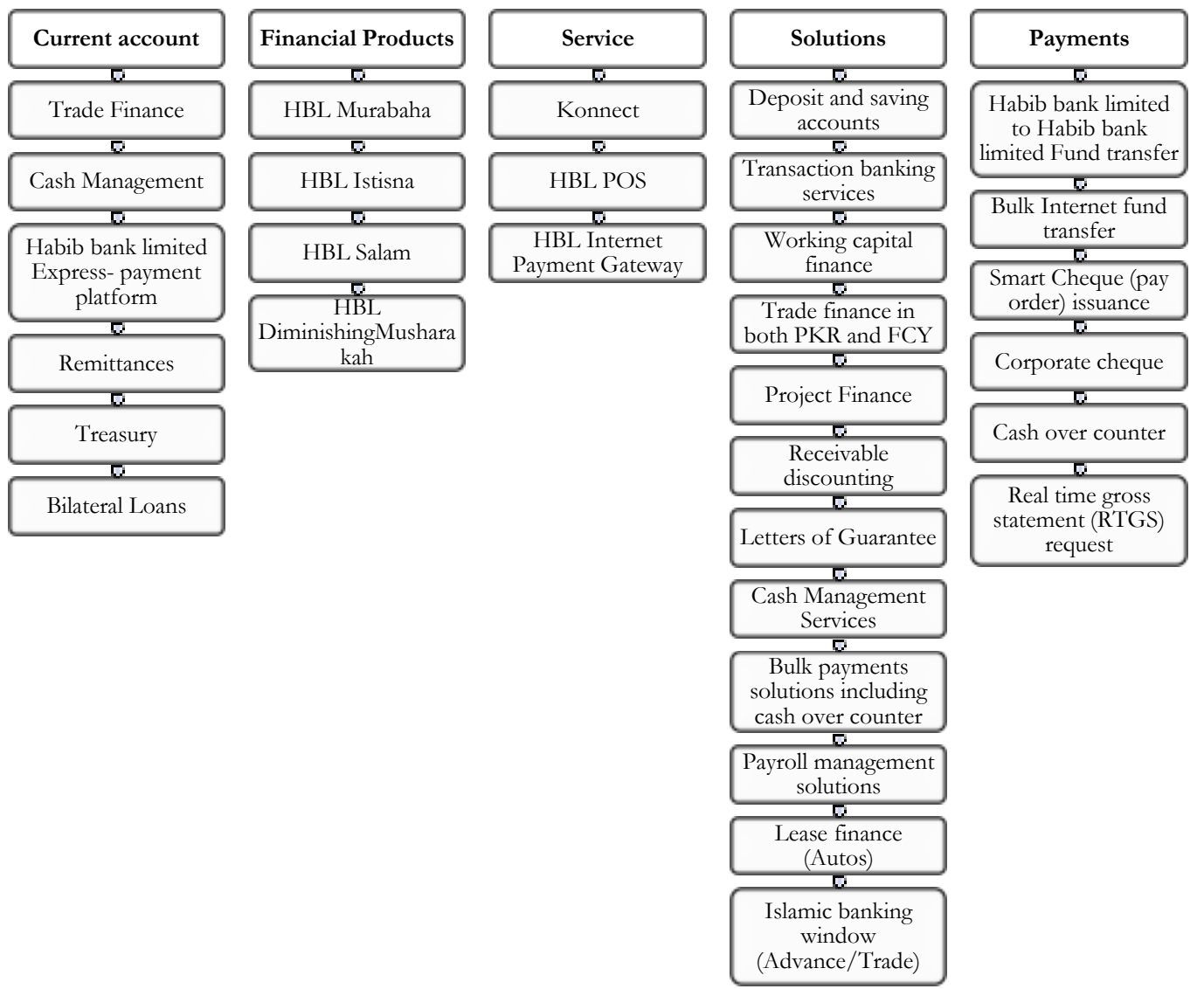

Partners.

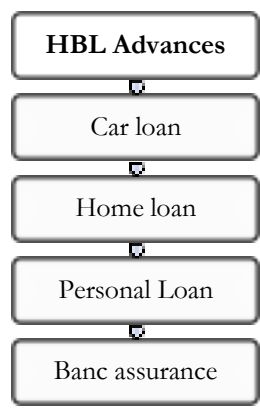

Figure 5: HBL Range of Products and Services 


\section{CASE METHODOLOGY}

The key tenacity of this research is to examine the effective relationship between job commitment, satisfaction and loyalty within banking sectors. With the help of interview from head of talent acquisition, the data is collected for this study. The methodology covers the research design which is used to understand the job commitment, satisfaction and loyalty in banking sectors. It is important for organizations to pay right focus and commitment on producing the effective work atmosphere for reducing employee's self-actualizations level. It can be stated that satisfaction can improves the quality of outputs and upsurges efficiency as it can also provoke the loyalty and confidence in employees. Fulfilled personnel incline to distinguish that the organization more ample in the long run, carefulness about the value of work and more dedicated to the organization, foremost to a protest of organizational social responsibility behaviors'. However, it can be stated that employees with high satisfaction have high rate of retention and are always productive. Whilst, the satisfaction has higher retention rates, work frustration can affect the mental and physical health of the employees

In adding, troublesome schedules influence employee efficiency in that monotonous long working hours get employees drained. Furthermore, the associations between managers and employees can be weakened due to poor working conditions. Same like this, the ineffective atmosphere can also affect the co-operation, self-confidence and employee's talent for dealing with resourceful philosophies. Hence, working environments can understood as an influential aspect in educating the enactment of both the individual employee as well as the organization. Job security has also been termed to have an effect on complete fundamental enactment. Organizations that compromise low job security cause their personnel to lose trust in their forthcoming in the organization. While employees who relish high job, security are more probable to accomplish their responsibilities efficiently, that reflected on the organization's performance.

\section{Main Discussion}

We briefed Mr. Saleem Shoukat Ali, who is a Head of Talent Acquisition - wholesale banking \& support functions at Habib Bank Limited with more than two years of experience in the relevant field about our research work. The objective of interview is 'Szabist's MSPM Subject Theories of Management - final Research report' that this interviewed is being carried out and reviewed by the subject lecturer. The procedure selected is based on verbal enquiry, discussing factual accuracy of information shared during the interview and judgement on the views of Head of Talent Acquisition. Following information was gathered:

- Salary is important for need and Job satisfaction is entirely different. It's about openness, culture, impact of mental prospect of employee engagement. Nature of relationship between employee and organization. In HBL they measured Job security and level of satisfaction through engagement survey, they recently conducted that type of survey and luckily, they received very good percentage.

- $\quad$ The culture provided to employee is unique and open culture they follow Ethics of working on diversity, approx. 20\% females currently working in Habib bank limited. They further replied on the level of satisfaction in banking sector that they don't quantify because it's very lucrative and risk culture.

- The more flexible hours employee may avail, they feel relaxed. Due to traffic, employees may stick so they may get extra half an hour leverage time to come office and yes because of this employee may satisfied with this working hour policy they may easily avail it.

- An unreasonable amount of stress was more related to competition and targets. Employees don't take it 100 percent for the achievement of task because the task is distributed 
equally from top to bottom. I was surprise to listen that HBL offer jobs around 350 more relevant employees per month. They also believe on cross-functional advancement. He further elaborates that in banking sector, sales targets are very different. High inflation creates difficult time in any organization. They have policies, supervisors, culture, and openness. Relationship manager build relationship among employees so they feel freedom.

- Senior authorities encourage employee for best effort that it depends on the leadership technology. Saleem thinks on employee recognition that different ends have lots of factors, fear treatment fruitful discussion if we don't engage supervisor in feedback. Employees at HBL are very much happy to be working for the same organization the lowest ratio of quitting the job is seven percent and it's a very minimal ratio.

- Saleem had specifically notified that the areas of psychosocial development and career development parts of counselling involve providing direction, role modeling. Career counsellor often involves training, interacting, and growth of the mentee in the professional world.

- Make it clear to people that you are leaving where the door open and do right or wrong without your direction, and most people will respond by doing right.

\section{Tangible Outcomes}

- It is essential that bosses to deliberate organizational commitment and job satisfaction apprehensions such as functioning environments, reasonable compensation plan, and gratefulness aimed at accomplishment, job enhancement, and employees' feelings of security and loyalty. Great organizational commitment and job satisfaction level of employees enables them to be encouraged.

- Communication flaw between maximum numbers of managers did not have accessibility about it, and then non-equipping of particular conflict treatment transforms skill make considerable difference to organization objectives and employee satisfaction.

- Employee satisfaction and commitment acquired definitely, week influence by mechanisms, alongside extreme dissimilar degree of superficial leadership \& satisfaction on associating by organization position levels. Management with transformational changes inspire employee to be innovative \& creative in such a way to think beyond the boundaries and convert new ideas that appreciated for organizations.

- Transformational leadership in banking sector has not revealed valuable occurrence, wherever importance conclusions encouraged that if managers embraced transformational urge substantively results sustains rewardingly.

- In existing self-motivated reformation of banking sector leaders with transformed skills must to sited, who can accomplish unusual means envisioned for new manners.

- Inclusive, this interview will really help us to write our case study, specifically in the area of banking sector. Additionally, we are able to understand about job satisfaction, commitment and loyalty in banking sector and their simultaneous relationship with Human Resource perspective.

\section{DISCUSSION}

The present research is to determine special effects of Human Resource practices on employee loyalty and assurance since job satisfaction as arbitration in banking sector of Pakistan. The banking area to improvement employee reliability, promise and job gratification. Result indications is important for top organizations that by what means they upsurge loyalty, commitment and job satisfaction. 
Training and development, performance evaluation, reward and assortment all evocatively defines the operative occupation gratification, commitment, and loyalty. Human Resource practices and job satisfaction, this study forms apprehensive about Human Resource Practices with loyalty, job satisfaction and commitment. The findings indicates, employee job satisfaction has an association \& keen effect of commitment and loyalty.

\section{CONCLUSION}

Job satisfaction and its influence on commitment and loyalty in banking sector is based on analysis of the study. Job satisfaction is not only effect by reward appreciation, contribution and enablement. Through model shows a significant and constructive relationship between the factors and job fulfillment. The study recommends that management can also consider other aspects of job satisfaction like job security, training and development, employees are allowed to contribute \& express themselves in decision, workplace environment, interactive association between supervisors and subordinates is a technique to construct advanced level of job satisfaction and commitment of employees. The management of bank in Karachi exercise this type of direction. The result of study concludes that if organization adopt openness, they can get better-fulfilled, committed, and loyal personnel.

\section{Limitations}

The factors considered in this exploration in various ways particularly work results. For example, work fulfillment, duty and dependability. Accordingly, a few constraints with respect to this examination were additionally considered and are explained beneath. To sum up the outcome we gather information, through interview, which is an essential wellspring of exact information assortment strategy. Survey may not be entirely solid to compute the loss surmising. Occupation fulfillment, duty and unwaveringness can be affected by numerous different factors too.

Time and money are two significant components, which assumed significant job in affecting the choices with respect to system of the examination. The time accommodated the investigation to get MS degree was not adequate to do nitty gritty research about these factors and on other hand, the analyst masterminded funds. Extending the extent of the exploration needs additional time and money. That is the reason the examination was restricted to a solitary division of bank and helpful inspecting was utilized for a similar explanation. That is why the research was limited to a single sector of bank and convenient sampling was used for the same reason.

\section{REFERENCES}

Al-dalahmeh, M., Khalaf, R., \& Obeidat, B. (2018). The effect of employee engagement on organizational performance via the mediating role of job satisfaction: The case of IT employees in Jordanian banking sector. Modern Applied Science, 12(6), 17-43.

Al-Sada, M., Al-Esmael, B., \& Faisal, M. N. (2017). Influence of organizational culture and leadership style on employee satisfaction, commitment and motivation in the educational sector in Qatar. EuroMed Journal of Business,12(2),163-188.

Ajmal, A., Bashir, M., Abrar, M., Khan, M. M., \& Saqib, S. (2015). The effects of intrinsic and extrinsic rewards on employee attitudes; mediating role of perceived organizational support. Journal of Service Science and Management, 8(04), 461-470. 
Bushra, F., Ahmad, U., \& Naveed, A. (2011). Effect of transformational leadership on employees' job satisfaction and organizational commitment in banking sector of Lahore (Pakistan). International journal of Business and Social science, 2(18).

Dajani, D., \& Zaki, M. A. (2015). The impact of employee engagement on job performance and organisational commitment in the Egyptian banking sector. Journal of Business and Management Sciences, 10(1).

Dhurup, M., Surujlal, J., \& Kabongo, D. M. (2016). Finding synergic relationships in teamwork, organizational commitment and job satisfaction: a case study of a construction organization in a developing country. Procedia Economics and Finance, 35, 485-492.

Faridi, A., Baloch, A., \& Wajidi, A. (2017). Job satisfaction and organizational commitment under Traditional and Modern T\&D program: Evidence from Public Banking Sector of Pakistan.

Faridi, A., \& Baloch, A. (2019). Training and development methods affecting professionalism and empowerment of banking sector employees. Journal of Management Sciences, 6(2), 75-92.

Jose, S., Zehra, N., \& Faizan, R. (2018). HR training's impact on the overall performances: A survey of budgeted hotels in India and Pakistan. International Journal of Applied Business and Management Studies, 3(1), 1-21.

Khuong, M. N., \& Tien, B. D. (2013). Factors influencing employee loyalty directly and indirectly through job satisfaction-A study of banking sector in Ho Chi Minh City. International Journal of current research and academic review, 1(4), 81-95.

Li, H., Sajjad, N., Wang, Q., Muhammad Ali, A., Khaqan, Z., \& Amina, S. (2019). Influence of transformational leadership on employees' innovative work behavior in sustainable organizations: Test of mediation and moderation processes. Sustainability, 11(6), 1594.

Mamdani, K. F., \& Minhaj, S. (2016). Effects of motivational incentives on employees' performance: A case study of banks of Karachi, Pakistan. South East Asia Journal of Contemporary Business, Economics and Law, 9(2), 32-39.

Ngari, J. M. K., \& Mukururi, J. N. (2014). Influence of work Life balance policies on employee job satisfaction in Kenya's banking sector; A case of commercial banks in Nairobi central business district.

Pitaloka, E., \& Sofia, I. P. (2014). The affect of work environment, job satisfaction, organization commitment on OCB of internal auditors. International Journal of Business, Economics and Law, 5(2), 10-18.

Shaheen, A., \& Farooqi, Y. A. (2014). Relationship among employee motivation, employee commitment, job involvement, employee engagement: A case study of University of Gujrat, Pakistan. International Journal of Multidisciplinary Sciences and Engineering, 5(9), 12-18.

Shaikh, T., \& Zahid, M. (2016). Retention Strategies to Increase Organizational Commitment and Reduce Employee Turnover in Hospitality Sector of Karachi, Pakistan.

Uzair, M., Razzaq, W., Sarfraz, M., \& Nisar, Q. A. (2017). Impact of HR practices on employee loyalty and commitment: Mediating role of job satisfaction. International Journal of Management Excellence, 9(2), 1067-1073.

Yousef, D. A. (2017). Organizational commitment, job satisfaction and attitudes toward organizational change: A study in the local government. International Journal of Public Administration, 40(1), 77-88. 